\title{
The Clinical Use of Mediator Release Test in Food
}

\section{Sensitivities}

\author{
Daria M. Adamczak ${ }^{1,2}$ \\ 1. Private Clinic Derma Solutions, Szczepankowo 94A, Poznan 61-306, Poland \\ 2. Poznan University of Medical Sciences, Coll. Maius, Fredry 10, Poznan 61-701, Poland
}

\begin{abstract}
Food sensitivities are non-IgE-mediated, non-coeliac, dose-dependent and delayed systemic responses to food. They consist of a highly complex class of adverse food reactions; however, their last phase is the release of mediators from leukocytes. The Mediator Release Test (MRT) is a functional measure of sensitivity-based inflammatory responses. It is an end-point test, which can account for the widest range of triggering mechanisms involved in sensitivity reactions, including both innate and adaptive pathways. MRT not only tests reactions to foods, food-chemicals, and other substances, but also reliably quantifies the degree of the inflammatory response. The test opens the new therapeutic options for food sensitivities.
\end{abstract}

Key words: MRT, adverse food reactions, food sensitivity.

\section{Food Sensitivities among the Adverse Reactions to Food}

There is a growing evidence of diet-induced inflammatory reactions, which has become a serious medical issue over the past 30 years [1-4]. Those abnormal responses affect ca. $20 \%$ of the population worldwide and may significantly reduce the quality of life $[5,6]$. The spectrum of diet-induces inflammatory reactions is very broad-from life-threatening anaphylactic shock to hardly noticeable food sensitivities. Although the nomenclature of adverse reactions to food is inconsistent and the same terms can be interpreted differently, they may be classified as immune mediated, non-immune mediated and toxic reactions. Among them I would like to distinguish food sensitivities. They can be defined as any non-IgE-mediated, non-coeliac reaction to a specific food or food additive, which generates inflammation. They are dose-dependent and delayed systemic responses occurring 24-72 h after ingestion. Food sensitivities involve multiple triggering mechanisms

Corresponding author: Daria M. Adamczak, MD, research fields: adverse food reactions, vitamin $\mathrm{D}$, and toll-like receptors. and leukocyte types, vast number of proinflammatory mediators, as well as wide array of symptoms and conditions. Therefore they consist a highly complex class of adverse food reactions [7].

\section{Symptoms and Conditions Related to the Food Sensitivities}

Food sensitivities cause wide range of symptoms and conditions. They are mostly confined to the gastrointestinal tract, but also other organs and systems may be involved as well. In order of simplification they are collected in Table 1 [8-13]. Food sensitivities generate a serious diagnostic problem, because the immune response is dose-dependent and most importantly, delayed. Therefore the patient does not link the symptoms with consumed food.

\section{Mechanisms of Food Sensitivities}

Mechanisms of food sensitivities are complex and engaged both innate and adaptive immunity. Important factors include the toll-like receptors, food antigens and chemicals, immune complexes (mainly IgG and IgM), as well as lectins. As a result cellular 
Table 1 Symptoms and conditions related to the food sensitivities.

\begin{tabular}{|c|c|}
\hline Gastrointestinal & Neurological \\
\hline $\begin{array}{l}\text { Abdominal pain } \\
\text { Bloating } \\
\text { Diarrhea } \\
\text { Irritable bowel syndrome } \\
\text { Crohn's disease } \\
\text { Ulcerative colitis } \\
\text { GERD } \\
\end{array}$ & $\begin{array}{l}\text { Migraine } \\
\text { Depression } \\
\text { Insomnia } \\
\text { Restless leg syndrome }\end{array}$ \\
\hline Metabolic & Gynaecological \\
\hline $\begin{array}{l}\text { Metabolic syndrome } \\
\text { Diabetes mellitus type II } \\
\text { Obesity }\end{array}$ & $\begin{array}{l}\text { Polycystic ovary syndrome } \\
\text { Infertility }\end{array}$ \\
\hline Musculoskeletal & Dermatological \\
\hline $\begin{array}{l}\text { Chronic fatigue syndrome } \\
\text { Fibromyalgia } \\
\text { Rheumatoid arthritis }\end{array}$ & $\begin{array}{l}\text { Atopic dermatitis } \\
\text { Urticaria } \\
\text { Psoriasis }\end{array}$ \\
\hline
\end{tabular}

activation of all leukocyte types occurs. It leads to release of the mediators-cytokines (interleukins, chemokines, tumour necrosis factors), leukotrienes, histamine and prostaglandins. The pathophysiologic effects such as inflammation, tissue damage, pain receptor activation, small muscle contraction and excess mucous production are the consequences of this cascade.

\section{Standard Food Sensitivity Blood Tests}

Commercially available blood tests are typically limited to a single mechanism or a specific part of the inflammatory process, which may or may not be involved in actual inflammation and therefore its clinical value is limited. Moreover the antibody tests (IgG, IgM, IgA) have not demonstrated an acceptable correlation with inflammation or clinical symptomatology in adverse food reactions. Those antibodies appear to be related to the clearing of food antigens and macromolecules via immune complexes, rather than a direct inflammation-producing role. The inflammatory effects of food-specific antibodies are the result of production of too many smaller immune complexes or complexes that deposit on tissue, eliciting an aggressive reaction by immune cells. Other limitations of non-IgE antibody tests are that they do not offer testing for food-chemical reactions, an area that is often clinically significant $[14,15]$.

\section{Mediator Release Test}

Mediator Release Test (MRT) is an innovative method for the detection of food hypersensitivities. It was invented and patented by an immunologist Mark Pasula (Oxford Biomedical Technologies). MRT is a refined version of the ALCAT test [7]. It utilizes a combination of advanced flow cytometry and the ribbon impedance method. The MRT tests cellular end-point reactions to foods, chemicals, and other foreign substances, quantifying the degree of the inflammatory response and simultaneously determining which types of cells are reacting.

\section{Basics of the Method}

Firstly, patient's blood is incubated with standardized antigens. Afterwards, if the substance is reactive, the mediators from leukocytes are released. MRT measures volumetric changes in all circulating white cells after antigen challenge.

\section{The Ribbon Method and Flow Cytometry}

The ribbon method is a patented form of impedance-based measurement. It eliminates the baseline and threshold associated with every other impedance-based sizing technology. It is extremely precise, measuring the entire flow of liquid and cells millions of times per second as they pass through the aperture. Because the ribbon identifies the true starting point and ending point of each cell, it is able to provide a volumetric determination of all tested cells. The flow cytometry allows distinguishing all leukocyte types. The combination of both methods enables to determine which cells react to a given antigen.

\section{The Final Result}

MRT assesses the reactivity of 150 most common foods and food additives. The test results are presented in the form of a diagram. It is individual for each patient. The un-reactive, safe foods are marked in green, slightly reactive are yellow and highly reactive 
red. MRT allows introducing LEAP (Lifestyle, Eating and Performance) ImmunoCalm Program. Its assumptions are to eliminate the harmful products and food chemicals from diet and subsequently to calm down the immune system. "Yellow" foods should be set aside for 3-6 months and the "red" ones should be avoided even for 3-4 years. The patient can also implement a new nutrition style by choosing best ("green") foods. However, it is very important to have a varied diet even if it consists only of the unreactive products. Otherwise the immune system may start respond to them.

\section{Acknowledgement}

I would like to thank Victoria Krzywicki and Peter Szafaryn from Poznan University of Medical Sciences, Center for Medical Education in English for their editorial assistance.

\section{References}

[1] Nowak-Wegrzyn, A., Sampson, H. A. 2006. "Adverse Reactions to Foods.” Med. Clin. North. Am. 90 (1): 97-127.

[2] Skypala, I. 2011. "Adverse Food Reactions-An Emerging Issue for Adults.” J. Am. Diet. Assoc. 111 (12): 1877-91.

[3] Kim, E. H., and Burks, W. 2015. "Immunological Basis of Food Allergy (IgE-Mediated, non-IgE-Mediated, and Tolerance).” Chem Immunol Allergy 101: 8-17.

[4] Dupont, C. 2011. "Food Allergy: Recent Advances in Pathophysiology and Diagnosis.” Ann. Nutr. Metab. 59 (s1): 8-18.

[5] Schäfer, T., Böhler, E., Ruhdorfer, S., Weigl, L., Wessner, D., Heinrich, J., et al. 2001. "Epidemiology of Food
Allergy/Food Intolerance in Adults: Associations with Other Manifestations of Atopy.” Allergy 56 (12): 1172-9.

[6] Turnbull, J. L., Adams, H. N., and Gorard, D. A. 2015. "Review Article: The Diagnosis and Management of Food Allergy and Food Intolerances.” Aliment Pharmacol Ther. 41 (1): 3-25.

[7] Pasula, M. J. 1993. "The ALCAT Test: In Vitro Procedure for Determining Food Sensitivities.” Folia Med. Cracov. 34 (1-4): 153-7.

[8] De Giorgio, R., Volta, U., and Gibson, P. R. 2016. "Sensitivity to Wheat, Gluten and FODMAPs in IBS: Facts or Fiction?” Gut. 65 (1): 169.

[9] Ho, M. H. K., Wong, W. H. S., and Chang, C. 2014. "Clinical Spectrum of Food Allergies: A Comprehensive Review.” Clin. Rev. Allergy Immunol. 46 (3): 225-40.

[10] Gibson, P. R., Varney, J., Malakar, S., and Muir, J. G. 2015. "Food Components and Irritable Bowel Syndrome." Gastroenterology 148 (6): 1158.

[11] Sicherer, S. H., and Leung, D. Y. M. 2015. “Advances in Allergic Skin Disease, Anaphylaxis, and Hypersensitivity Reactions to Foods, Drugs, and Insects in 2014.” $J$. Allergy Clin. Immunol. 135 (2): 357-67.

[12] Sampson, H. A., and Anderson, J. A. 2000. "Summary and Recommendations: Classification of Gastrointestinal Manifestations due to Immunologic Reactions to Foods in Infants and Young Children.” J. Pediatr Gastroenterol Nutr. 30 Suppl: S87-94.

[13] Sampson, H. A. 2003. “Food Allergy.” J. Allergy Clin. Immunol. 111 (2): S540-7.

[14] Carr, S., Chan, E., Lavine, E., and Moote, W. 2012. "CSACI Position Statement on the Testing of Food-Specific IgG.” Allergy Asthma Clin Immunol. 8 (1): 12.

[15] Boyce, J. A., Assa'ad, A., Burks, and A. W. 2010. "Guidelines for the Diagnosis and Management of Food Allergy in the United States: Report of the NIAID-Sponsored Expert Panel.” J. Allergy Clin. Immunol. 126 (6): S1-58. 